\title{
Modelling the implied volatility of options on long gilt futures
}

Article

Accepted Version

Brooks, C. and Oozeer, M.C. (2002) Modelling the implied volatility of options on long gilt futures. Journal of Business Finance and Accounting, 29 (1-2). pp. 111-137. ISSN 14685957 doi: https://doi.org/10.1111/1468-5957.00426 Available at https://centaur.reading.ac.uk/24154/

It is advisable to refer to the publisher's version if you intend to cite from the work. See Guidance on citing.

To link to this article DOI: http://dx.doi.org/10.1111/1468-5957.00426

Publisher: Blackwell Publishing Ltd

All outputs in CentAUR are protected by Intellectual Property Rights law, including copyright law. Copyright and IPR is retained by the creators or other copyright holders. Terms and conditions for use of this material are defined in the End User Agreement.

\section{www.reading.ac.uk/centaur}

\section{CentAUR}

Central Archive at the University of Reading

Reading's research outputs online 
This is the authors' accepted manuscript of an article published in the Journal of Business Finance and Accounting. The definitive version is available at www3.interscience.wiley.com 


\title{
Modelling the Implied Volatility of Options on Long Gilt Futures
}

\section{Chris Brooks $^{1}$ and M. Currim Oozeer ${ }^{2}$}

\begin{abstract}
This paper investigates the properties of implied volatility series calculated from options on Treasury bond futures, traded on LIFFE. We demonstrate that the use of near-maturity at the money options to calculate implied volatilities causes less mis-pricing and is therefore superior to, a weighted average measure encompassing all relevant options. We demonstrate that, whilst a set of macroeconomic variables has some predictive power for implied volatilities, we are not able to earn excess returns by trading on the basis of these predictions once we allow for typical investor transactions costs.
\end{abstract}

November 2000

Keywords: implied volatility, options on bond futures, trading rule, macroeconomic predictors, out-of-sample forecasting.

\section{JEL Classifications: C22, G13}

\footnotetext{
${ }^{1}$ Corresponding author; tel: 011893167 68; fax: 011893147 41; e-mail: C.Brooks@ @eading.ac.uk

2 The authors are both members of the ISMA Centre, Dept of Economics, University of Reading, Whiteknights, PO Box 242, Reading, RG6 6BA, United Kingdom. The authors are grateful to an anonymous referee for useful comments on a previous version of the paper. The usual disclaimer applies.
} 


\section{1: INTRODUCTION}

Since the introduction of the Black-Scholes model for the pricing of derivative securities in 1973, there has been a proliferation in the number of studies which have sought to test the accuracy of their formulation and to extend it, for example for pricing derivatives whose underlying assets pay a dividend. In order to use any pricing model to value an option, an estimate of the volatility of returns to the underlying asset is required, and if, for example, one were to use the Black-Scholes formula, this is the only quantity that one would need to estimate, since all the other variables required are directly observable from the market. As a result, the relevance of any pricing model will depend on one's ability to accurately estimate or forecast the volatility of the underlying asset.

Initially, estimates of the historic standard deviation were used to calculate the price of an option for simplicity and since it was assumed that historic standard deviation was the best estimate of future standard deviation. However, if the history of returns on the underlying asset, or the option's market price contain information that can be used to calculate better indicators of future return volatility, then the estimate of volatility using historical standard deviation would cease to be a best predictor. Thus, the primary motivation for recent interest in implied volatilities (by academics and practitioners alike) is that, as will be outlined below, many studies have shown that it is a far better predictor of future price variability, on average, than the historical volatility of the underlying security (see, for example, Canina and Figlewski, 1993; Day and Lewis, 1992; Jorion, 1995; Lamoureux and Lastrapes, 1993).

Most of the studies in this area have concentrated on options whose underlying asset is either a particular stock or stock index and very few researchers have looked at options on other underlying assets. Moreover, since options on futures are a relatively new class of securities in the field of derivatives, most previous studies have concentrated on models for valuation of these assets given their characteristics, rather than looking at the behaviour of the volatility series implied by the option. In this study we model the implied volatility of options on Long Gilt futures. An option on a futures contract is similar to any option in the sense that it gives its owner the right to enter either a long or 
short position in the underlying security at a fixed price known as the exercise price. Suppose that the holder has a call option, then upon exercise, he will get a futures contract with a futures price which is equal to the exercise price of the option. However, when he exercises the call option, there is no exchange of cash between the parties as it would happen for a stock option. As he holds a call option, he is delivered a long position in a futures contract. Since futures contracts are marked to market everyday at the close of trading, the option holder will be able to withdraw an amount which is equal to the futures price minus the exercise price if he had a call option or the difference between the exercise price and the futures price if he had a put option. Another interesting characteristic of this option is that the buyer of a call/put does not have to pay the premium at the time of purchase. The option position is marked-to-market every day (like a futures contract) and as such, the investor will be required to hold a margin account with the Clearing House, which will be adjusted everyday for any variation margin.

The remainder of this paper is organised as follows. Section 2 comprises a review of previous research that has been undertaken on implied volatility and we shall look particularly at research which studies options on futures. We then move on to outline the data employed and to review the characteristics underlying the option valuation model which we are using to calculate the implied volatilities in section 3. Having estimated the implied volatilities, we then model the behaviour of the change in implied volatility series using macroeconomic variables. Using the forecasts of the change in implied volatilities predicted by our model, we devise a trading strategy to exploit any profitable opportunities. The results from the options pricing, modelling of implied volatility series, and trading profitability are all presented in section 4 . Section 5 concludes.

\section{2: Review of the literature on implied volatility}


One of the first studies of implied volatility was undertaken by Latané and Rendleman in 1976. Their idea originated from a Black and Scholes (1974) paper which showed that the actual standard deviation of the underlying asset over the life of the option, suggested by the current option price, would be of more use for the valuation of a call than a pure historical average. Latané and Rendleman (1976, hereafter LR) assumed that investors price options according to the Black and Scholes model and were therefore able to use the actual call price to derive the implied standard deviation. If the assumptions of Black and Scholes hold and the options market is efficient, then all the options on a particular stock would be valued using the same estimate of the standard deviation and this would represent the market's forecast of the future variance of the stock's return. However, this is not the case, as some options are more dependent upon a precise specification of the standard deviation than others (Latané and Rendleman, 1976, p. 371). A change in the volatility of a stock's return would not affect all the options in the same way. Some are more sensitive to these changes than others and as a result they would provide a better estimate of the implied volatility of the stock. Thus, if the standard deviation for each option on a particular stock is different, the Black-Scholes (hereafter B-S) pricing formula would be redundant because one of its assumptions is that the standard deviation of stock's return is constant over time. As a result, it would seem that it is inconsistent to use the B-S formula to infer a changing implied volatility. However, the B-S valuation framework may still be relevant, (even though the constant variance assumption is violated in practice), since Hull and White (1987) showed that the B-S model's predictions for implied volatility, especially for options that are near to the money, are indistinguishable from models where volatility follows a stochastic process. Therefore, the implied volatility of each option will depend on the characteristic of that particular option and as such, a simple arithmetic average of the implied volatility of all the options that are written on the stock would not be representative of the market's forecast of that stock's return variability. In order to obtain a single estimate of the implied volatility, LR suggested a weighted implied standard deviation (WISD) where more weight would be given to the implied volatility of options whose values are theoretically more sensitive to the standard deviation. 


$$
W I S D_{i t}=\frac{\left[\sum_{j=1}^{N} I S D_{i j t}^{2} \bullet d_{i j t}^{2}\right]^{0.5}}{\sum_{j=1}^{N} d_{i j t}}
$$

where $W I S D_{i t}$ is the weighted average implied standard deviation for company $i$ in period $t, I S D_{i j t}$ is the implied standard deviation for option $j$ of company $i, N$ is the number of options on company $i$ at time $t$, and $d_{i j t}$ is the Partial derivative of the Black-Scholes valuation formula with respect to the implied standard deviation of option $j$ of company $i$ in period $t$. The weights used to derive the weighted average implied standard deviation are the partial derivatives of the Black-Scholes equation with respect to each implied standard deviation ${ }^{3}$.

Since this early research, the volume of the literature on the calculation of implied volatility has grown considerably. Researchers are in broad agreement that implied volatility yields superior forecasts of return variability, but are unsure of how to calculate it properly; for example, they do not know whether to use only one option or whether to use a weighting scheme to calculate the implied volatility. The study undertaken by LR was also simplistic in the sense that it did not take into account dividend payments when valuing the options, since they employed the original B-S pricing formula and one of its assumptions is that stocks do not pay dividends. As a result many studies have tried to improve on the original idea of LR, and one such study was undertaken by Beckers (1981). Not only was the effect of dividends on option prices taken into account, but also a new weighting scheme was introduced, which placed more emphasis on at the money options. He calculated a single estimate of the implied standard deviations by minimising the weighted sum of the squared deviations between the market value and the corresponding B-S price, where each implied standard deviation was weighted by the partial derivative of the B-S formula with respect to the standard deviation. The formula he derived was as follows:

\footnotetext{
${ }^{3}$ Schmalensee and Trippi (1978), have shown that tests done on the Latané and Rendleman weighting scheme for a variety of parameters give little weight to options that are deep in or out of the money and have a short time to maturity.
} 


$$
I S D=\sum_{i=1}^{N} \mathcal{W}_{i}\left[C_{i}-B S_{i}(I S D)\right]^{2} / \sum_{i=1}^{N} w_{i}
$$

where $C_{i}$ is the market price of option $i, B S_{i}$ is the Black-Scholes option price as a function of the ISD, $N$ is the total number of options on a given stock with the same maturity, and $w_{i}$ is the partial derivative of the Black-Scholes option pricing formula with respect to the standard deviation.

For comparison with previous research, he also tested the predictive ability of the at the money implied standard deviation. He found that although this new implied volatility measure was a much better predictor of future variability than the historic standard deviation, when compared to the at-themoney implied standard deviation, the latter was the better predictor. According to Beckers, this shows that a weighting scheme for computing a single estimate of the ISDs may not be useful after all and that by adding the implied volatility of other options to the at-the-money implied volatility this could only worsen the predictive power of the latter, since most of the information about future volatility is reflected in the price of the at-the-money options. In this study, we are guided by the conclusions of previous research, and we therefore employ only at-the-money options, and not a weighted combination of at-the- and far-from-the-money.

\section{3: Data \& Methodology}

\section{1: Options Data and Sources}

Although most of the research in this area has been undertaken using data on US Treasury bonds futures which are traded on the Chicago Board of Trade (CBOT), we model options futures using data from the London International Financial Futures Exchange (LIFFE). We focus on the implied volatilities of options on Long Gilt Futures, the underlying asset for which is one of the most popular and liquid futures contracts traded on LIFFE. These options, known as regular options, started trading in March 1986 and the contract maturity is the same as the underlying Long Gilt futures contract i.e. March, June, September, December. The only difference between the two is that the option expires 6 business days before the delivery month of the futures contract i.e. an option on the March futures contract would expire around the $22^{\text {nd }}$ of February while the futures contract would expire two 
business days prior to the last business day in the delivery month. Moreover from March 1995, additional options, known as serial options, were introduced such that from that date a contract expires every month instead of every 3 months. The data from LIFFE is separated according to maturity and for each option maturity we obtained the closing price of all the options that were traded on any particular day for that maturity, from the first day that the option started trading to its expiration. We utilised daily closing price data for this study since intra-daily data for LIFFE options on bond futures was not available for most of our sample period. We employed the yield on 3 month Treasury Bills as a proxy for the short term risk-free interest rate.

In our analysis, we calculated the implied volatility only for the at the money call options with the shortest maturity but with at least 15 days to expiration. We ignore the last 15 days of trading because options markets are very volatile during this period, which could lead to unreliable estimates of implied volatility. Thus, we were able to obtain a time series of implied volatilities from March 1986 to the end of March 1996.

We use the closing price of the option to calculate the implied volatility, and as Stoll and Whaley (1991) pointed out, this could potentially result in "non-simultaneous" prices being used for the calculation of the implied volatility and therefore inducing negative first order serial correlation in the implied volatility change series. However, their study was based on US derivatives exchanges and there is a difference in the closing times of the stock exchange and the options market. In our case, both the options and the underlying markets close at the same time and therefore the chance of nonsimultaneity in the prices occurring is small.

\subsection{Calculating the Implied Volatilities}

Since we are trying to model the implied volatility of options on Long Gilt futures we need to use a valuation formula to derive the implied volatility series. The first study undertaken in this area was by Black (1976) and although he considered options on forward contracts, his results can be applied 
to futures contracts when the short term interest rate is non stochastic, because then the value of a forward contract is equal to that of the corresponding futures contract. Moreover, Barone-Adesi and Whaley (1987) pointed out that the partial differential equation derived by Black is so general that it can be used to describe the price dynamics of not only European call options but European puts and American options as well. In this section, we demonstrate that Black's formula is still useful and that it can be employed to calculate the implied volatility series. We start by explaining its basic framework.

In order to develop Black's European valuation formula the following assumptions must be made:

(1) There are no transactions costs and short sales are permitted

(2) The short term interest rate is constant through time.

(3) The change in the instantaneous futures price is described by the stochastic differential equation;

$$
d F / F=\mu d t+\sigma d z
$$

where $\mu$ is the expected instantaneous price change relative of the futures contract, $\sigma$ is the instantaneous standard deviation, and $z$ is a Weiner process.

Examining the plausibility of these assumptions, the first should not give cause for concern since in real life market makers have small or no transaction costs. The second assumption of a constant short term interest rate could at first sight appear contradictory to our basic methodology. This is because the main factor affecting the volatility of bond prices or bond futures is interest rate uncertainty. It would therefore seem incorrect to use the Black formula to price options on bonds futures. However, our study is centred on options on long bond futures and the driving force behind the volatility of the T-Bond futures prices is the long term treasury bond rate and not the short term rate which we assume to be constant. We only consider short maturity options, and the cheapest to deliver (CTD) bond hardly changes with interest rates over the life of the bond. Barone-Adesi and Whaley (1987) suggested that these two rates are to some degree separable. Even though the contracts do contain delivery options, the CTD bond changes very little over the life of the option. Some studies have tried 
to solve this problem by using stochastic interest rate processes to model option prices (Ramaswamy and Sundaresan (1985)), although these have had limited success since the model will only be realistic if the interest rate process posited is accurate enough. A further important problem with these stochastic models is that they have to be solved numerically as no closed form solutions exist.

The third assumption describes the dynamics of the futures price movement through time. As pointed out by Barone-Adesi and Whaley (1987), there is no reference to the relationship between the futures price and the underlying spot commodity in the equation and as such this valuation formula can be applied to any futures contract. According to Cakici et al (1993), if the cost of carry relationship holds, then the assumption that the futures price follows a stochastic differential equation will be consistent with the assumption that the underlying asset also follows a stochastic differential equation;

$$
d S / S=\alpha d t+\sigma d z
$$

where $\alpha$ is the expected relative spot price change, $\sigma$ is the instantaneous standard deviation, $z$ is a Weiner process. However, in the case of bond futures the cost of carry relationship is not straight forward because of the presence of delivery options (on quality and timing) and as such the stochastic differential equation of the underlying asset would be different from the one above.

By making these assumptions and forming a riskless hedge which consisted of the futures option and its underlying futures contract, Black was able to derive a partial differential equation that determines the path of the future options price $(V)$ :

$$
\frac{1}{2} \sigma^{2} F^{2} V_{F F}-r V+V_{t}=0
$$

where $V$ is the futures option price, $F$ is the current futures price, $r$ is the risk free rate of interest, $\sigma$ is the instantaneous standard deviation, $V_{F}$ and $V_{F F}$ are the first and second derivatives of the option price with respect to the price of the futures contract, and $V_{t}$ is the derivative of the option price with respect to time. 
As mentioned above, this equation is so general that it can be used to value either European and American options and either call or put options. For example, when using the boundary condition of a European call option, the terminal value of a call option being the max $(0, F-X)$, Black was able to solve the above equation to obtain the following formula for valuing a call option on a futures contract

$$
c(F, T, X)=e^{-r T}\left[F \times N\left(d_{1}\right)-X \times N\left(d_{2}\right)\right]
$$

where $d_{1}=\left[\ln (F / X)+0.5 \sigma^{2} T\right] /\left(\sigma T^{1 / 2}\right), d_{2}=d_{1}-\sigma T^{1 / 2}, F$ is the current futures price, $X$ is the strike price of the future option, $T$ is the time to expiration of the option, $N$ is the cumulative normal distribution, $r$ is the risk free rate. In this study, we assume that call options on bond futures are priced according to the formula in [6].

However, one potential problem is that we are using a formula derived for the valuation of European options to value an American option on a futures contract. Studies have shown that the early exercise feature of an American option can result in American options having a slightly higher premium than a similar European option, as demonstrated by Barone-Adesi and Whaley (1987). He showed that as the value of the underlying future contract becomes very large relative to the exercise price, the values of $N\left(d_{1}\right)$ and $N\left(d_{2}\right)$ approach one. From expression [6] above, we see that the value of a European call approaches $e^{-r t}[F-X]$, however the value of a similar American option is $[F-X]$ as it can be exercised immediately. This shows that the American option has a higher value than its European counterpart and as such will command a higher premium.

A number of solutions have been proposed for this problem. For example, researchers have tried to solve the Black partial differential equation ([5] above), but subject to the American call option on a futures contract boundary condition. However, no analytic solution has been found and hence researchers have tried to value American futures options using a finite difference approximation method. This method is computationally expensive and one needs to enumerate every possible path 
that the futures option price may take during the life of the option before one can use it. BaroneAdesi and Whaley (1987) were able to derive a quadratic approximation for the pricing of American options and according to them it is considerably faster than the finite difference method. Their formula is complex and involves the estimation of the critical futures price where one would exercise the American option immediately.

There is fortunately some empirical evidence, however, that suggests that the Black formula is still valid for certain options. Brone-Adesi and Whaley (1987) carried out a simulation of the early exercise premium values. Using a range of option pricing parameters, they calculated the option prices using the quadratic and finite difference approximations. They found that for out of the money options, the early exercise premium is negligible and even for at the money options the early exercise premium represents only a very small percentage indeed of the American option price. It is only for options that are deep in the money that the early exercise premium is non-negligible. Taking the results of this simulation into consideration, it would seem that we can validly use the Black formula to derive the value of at the money American call options.

These simulations results were confirmed by a study undertaken by Cakici et al (1993), using both valuation models to price options on T-Note and T-Bond futures. Again, comparing model prices to actual prices, they also found that it was only options that are in the money which are underpriced by both models and they found no mispricing with regards to out of or at the money options. Their conclusion was that Black's (1976) European pricing model is indistinguishable from the American pricing model of Barone-Adesi and Whaley (1987) for pricing options on T-Bond and T-Note futures.

In this study we use the at the money options to calculate the implied volatility and since we cannot calculate the volatility by solving the Black formula directly (since it is a nonlinear equation), we use an iterative search procedure, the Newton Raphson method, to solve for the volatility implied by the option price. 


\section{3: The Estimated Implied Volatilities}

Using Newton-Raphson, we are able to derive a time series of implied volatilities estimates and table 1 reports some preliminary analysis on the data. The table reveals that the mean of the implied volatilities over the entire period of 10 years is 0.092 and the variance is 0.0001 . The kurtosis test is insignificant i.e. there does not seem to be any evidence of fat tails but the data is skewed to the right. Looking at the results for the change in implied volatility we see that the mean for the series is 0.0002 and the variance is 0.003 . The change in implied volatility series is more volatile than the level of implied volatility series. However the change series is both skewed and leptokurtic, implying that the distribution of returns has fatter tails than a normal with the same mean and variance. The change series is also skewed to the right. This leads the Bera-Jaque normality test to reject the Gaussian null convincingly.

Figures 1 and 2 show the implied volatility and change in implied volatility series respectively over the sample period (March 1986 - February 1996). The figures show a small number of large (positive or negative) spikes, where implied volatility rose substantially, or fell to zero. These may be considered outliers, which correspond to the October 1987 stock market crash, and to times when LIFEE lost their record of prices for this option.

An important question to address for valid econometric analysis of any time series is whether the data can be considered stationary or whether it contains a unit root. Figure 1 suggests that the series could be non-stationary, since it exhibits "long swings" with very few mean-crossings. However, the Dickey Fuller test results shown in table 1 indicate a clear rejection of the unit root null hypothesis in the levels series. Conversely, the autocorrelation coefficients for the levels series decline very slowly indeed, and are significant beyond the 50th lag. This would imply that a very large number of lags of the dependent variable would be required in the model to soak up this autocorrelation and consequently we concentrate on innovations in implied volatility for subsequent analysis. 
Additionally, both the levels series and the changes show strong evidence of ARCH-effects, and hence heteroscedasticity-robust standard errors are used in all ensuing analysis.

\section{4: Information variables used in predicting implied volatility}

In this section, we briefly explain the variables that are used for modelling the implied volatility series. For determining the appropriate conditioning variables for forming a time series model of the change in implied volatility, we draw on previous research, although most of the previous studies have modelled stock return volatilities rather than implied volatilities. Only one modelled implied volatilities, and the underlying asset in that case was a stock index (Franks and Schwartz (1991)). The variables employed therein are similar to those commonly used to predict stock returns, and comprise a set of macroeconomic variables, usually tested within an APT-type framework.

Following Elton et al (1995) and the references therein, the main variables that have been regularly used by academics are:

(1) Excess market returns

(2) Default risks (Difference in returns between corporate bonds and government bonds)

(3) Term risks (Difference in returns between long and short term government bonds)

(4) Unexpected changes in inflation

(5) Unexpected changes in a measure of economic performance.

Although these variables have all been used at one point or another to explain stock return variability, we think that they will still be relevant in explaining bond volatility. The first variable 'excess market return' can be seen as a general measure of economic conditions and confidence. It is the difference between the return on the stock market and the risk free rate of return. It can also be viewed as a catch-all for omitted variables (see Elton et al, 1995). The second variable is not relevant in this case, since we are modelling government rather than corporate bonds. The third variable is a proxy for the term structure of interest rates (interest rate risk), and is measured as the difference between the yields on long term government bonds and the 3 month T-Bill rate. Another variable that can be used to 
represent economic conditions is unexpected changes in inflation. Elton et al (1995) argued that changes in this variable should affect the level of interest rates and therefore bond returns. The final factor that they mentioned as popular can be proxied by variables that represent economic conditions prevailing in the country such as industrial production, in other words economic factors found significant in tests of the arbitrage pricing theory. We employ all of these variables in our modelling, although we only report those that are significant.

We use the dividend yield on the FT-All Share index to act as a proxy for the general economic condition in the UK. Following, Clare and Thomas (1992) who found that a country's bond return can be explained by both the country's term structure and the US term structure we use first the UK term structure (measured by the difference between the yield on British Government irredeemables (acting as a proxy for the long bond yield) and the 3 months UK Treasury Bill discount rate (proxy for the short term interest rate)) only, and then both the UK and US term structure to model implied volatility. We also use the variable known as GEYR, (see Levin and Wright, 1998), which is a relative measure of the expensiveness of bonds relative to equities. It is calculated by dividing the long bond yield by the dividend yield of a stock index and is an indicator of the expensiveness of gilts yields relative to equity yields.

Another variable that has been used to explain changes in volatility is changes in volume (see Brooks, 1998 for a survey of this literature). As Franks and Schwartz (1991) pointed out, the impact of new information can be evaluated through price changes but changes in volume will tell us whether investors agree with the interpretation of the information.

The regression results presented below also include day-of-the-week dummy variables to determine whether there are any seasonal patterns in the implied volatility series. Harvey and Whaley (1992) suggested that Monday's implied volatility should be higher than on other days since traders open positions for the on the first trading day of the week, meaning that there is excess buying pressure on 
Mondays resulting in higher volatility. Finally, other studies (such as Engle, 1982) have shown that because of strong persistence in the volatility series, we need to include lags of the dependent variable to allow for the dynamic structure of the series.

\section{4: Results}

This section is divided into three parts and presents the findings of the various tests outlined in the previous section. The first set of results looks at the performance of the option pricing model by checking for any systematic patterns in the mispricing errors. This is followed by a summary of the regression results obtained from modelling the change in implied volatility series. Having found a set of significant information variables, we use the resultant model to see whether it is possible to earn excess returns from devising a trading strategy. Thus the last part of this section is a summary of the profits or losses made from the trading exercise.

\section{1: Tests for systematic biases in the pricing model}

As mentioned in the previous section, we are using a European option pricing model to approximate the price of an American option. In order to know the extent of the mispricings, we calculate the price of the option first using an option pricing model, and then subtracting it from the actual market price. To calculate the model price we require an estimate of sigma $(\sigma)$ because the remaining four out of the five variables are either available from the market or the contract specification. In order to reduce any mispricings that could be the result of errors in the way we calculate sigma, we use the actual standard deviation of the underlying asset's return that occur during the life of the option in our model. Thus, our estimate of sigma for each option for each day is the standard deviation of the Long Gilts futures' returns from that day to the maturity of the option. For each option maturity (serial or regular option) we have a time series of standard deviation ranging from the day the option started trading to its maturity. 
By subtracting the model's price from the actual market price we were able to determine the mispricings errors for 95804 call options (the total number of calls on bond futures option traded from March 1986 to March 1996). In order to report the maturity and moneyness biases we first group them and then average the price deviations. To test for any moneyness biases, we divide the total sample into three groups: $F / K<0.98,0.98 \leq F / K<1.02$ and $F / K \geq 1.02$ where $F$ is the futures price and $K$ is the exercise price, and to test for any maturity biases we divide the sample into four groups $(T<3$ weeks, $3 \leq T<6,6 \leq T<12$ and $T \geq 12$ ). The absolute pricing errors are presented in Panel A of Table 2.

The major conclusion from Panel A Table 2 is that the Black pricing model seems to slightly underprice all options regardless of their moneyness and maturity. One possible explanation is that as expected the early exercise premium of American options is not being taken into account by the model. Although the mispricings are very small for most classes of options, there seems to be moneyness and maturity biases for certain options. When all the call options are aggregated by maturity (All $T$ in Table 2 above), only those that are deep in the money ( $F \geq 1.02$ ) seem to be significantly underpriced ( 0.160 in the All $T$ column), but the mispricing is more pronounced for these deep in the money options when they have a maturity of more than 12 weeks $(0.248)$. Moreover the same results (significant underpricing) were obtained for deep in the money options with 6 to 12 weeks to maturity. One reason for the significant underpricing is that the options are American so that they can and would be exercised immediately when deep in the money, and therefore their value will be higher than corresponding European options. Similar results are observed when the pricing errors are measured as a proportion of the actual options prices. These findings are presented in Panel B of Table 2. We find, overall, that mis-pricings for at the money short-maturity options are typically as low as $1 \%$ of the option value. Clearly, the systematic underpricing in certain circumstances is related to the model assumptions - first, because we have effectively ignored the early exercise premium. Second, and more subtly, Ho, Stapleton and Subrahmanyam (1997) have shown that stochastic interest rates have a positive effect on the option value. We have assumed that interest rates 
are fixed, whereas in reality they have a random influence, which if incorporated into the model, would have increased the option values.

Concurring with the study by Cakici et al (1993), we do not report any significant mispricings for options that are at or out of the money. However, we do find a small mispricing for at the money options that have more than 12 weeks to maturity $(0.116$ for $T>12$ with $0.98 \leq F / K<1.02)$. When all options are aggregated by maturity but still separated by moneyness (All $T$ column in table 2), the underpricing by the model increases linearly with moneyness (starting from 0.026 for out of the money options rising to 0.160 for deep in the money ones).

As for the maturity biases, only options with a maturity of more than 12 weeks seem to have a mispricing which could be economically significant $(0.144$ for All $F / K$ with a maturity of more than 12 weeks). These mispricings are more severe for deep in the money options ( 0.248 for $F / K>1.02$ ). Here again, when all the calls are aggregated by moneyness but still separated by maturity (row All $F / K$ in Table 2) the underpricing by the model increases linearly as the time to maturity of the options increases (starting from 0.022 for options with less than 3 weeks rising to 0.144 for options with more than 12 weeks ).

Our results are similar to those of Cakici et al (1993) since we found that significant mispricings only occur for deep in the money options. The moneyness biases seem to be more significant than the maturity biases. Overall we might have expected to obtain similar results to Cakici et al, as we use options on Long Gilt futures while they carried similar tests on options on T-Bond futures. The above results show that we are right in choosing to use only at the money options and also to ignore options with a maturity of less than 2 weeks when calculating the implied volatility. Moreover, most of the options that we use to calculate the implied volatility have a maturity of less than 12 weeks. Since, there are no significant mispricings for at the money options apart from those with a maturity of more 
than 12 weeks, then our estimate of implied volatility is not biased by the fact that we are using a European option pricing formula to approximate the value of an American option.

\section{2: Modelling changes in implied volatility}

Having explained how we arrived at the implied volatility figures in the previous section, we now explain the results achieved when the change in the implied volatility series is modelled using the general model:

$$
I V_{t}=\sum_{k=1}^{n} \beta_{k} X_{k, t-1}+\sum_{i=1}^{5} \gamma_{i} D_{i, t}+u_{t}
$$

where $I V_{t}$ is the implied volatility series, $X_{k, t-1}$ is the value of the $k^{\text {th }}$ macroeconomic variable at time $t-1, D_{i, t}$ is the daily dummy variable, taking the value 1 on day $i$ and zero otherwise, and $u_{t}$ is the disturbance term.

We started by looking for any seasonal patterns in both the level and change in implied volatility series. In order to do so, we have to carry a regression on five dummies, as we are checking for the day of the week effect. We also include lags of the dependent variable in the regression because previous studies have shown that there is persistence in the volatility series. The number of lags employed is that number required to render a Ljung-Box $Q^{*}(10)$ test on the residuals to be insignificant at the $5 \%$ level $^{4}$. We also include dummy variables to remove certain outliers, namely the stock market crash of 1987 and on dates when LIFFE lost their record of option prices.

The regression results presented in Table 3 show that none of the five seasonal dummies are significant for the change in implied volatility series but they are all significant for the implied volatility level series. As expected, implied volatility is at its highest on Mondays (daily average of 0.0020731 over the sample). Looking at the results for the change in implied volatility series, it would

\footnotetext{
${ }^{4}$ We find that 5 lags of the change in implied volatility are required. For the levels series, the autocorrelation is still present when 20 lags are included. Thus the model employing macroeconomic variables presented subsequently will be estimated only on the changes series, and incorporating the five lags.
} 
seem that there are no seasonal pattern as regards to the day of the week. Moreover, we see that volatility falls from Thursday to Friday by an average of 0.0005873 over the entire sample while it increases by 0.0005176 from Friday to Monday. The size of these changes in implied volatility do not seem to be large enough to be statistically or economically significant ${ }^{5}$.

We now present the results obtained when using the information variables outlined above to forecast the implied volatility series. The first regression contained only UK information variables, and these results are presented in column 3 of table 4 . It is evident that none of the UK information variables seem to be able to explain the change in implied volatility series apart from the lag of the change in implied volatility itself, and the dummy variables.

Following a study by Clare \& Thomas (1992), who found that information regarding US bond returns was a significant factor in explaining other countries' bond returns, we include the US term structure and the dividend yield of the S\&P 500 in the regression. The results shown in the last column of table 4 are quite surprising as the US term structure, which is defined as the difference between the 30 year Benchmark Bond redemption yield and the 3 month US Treasury bill discount rate, is a significant factor in explaining the change in implied volatility of UK Long Gilt futures options. This seems to be in line with the study undertaken by Clare \& Thomas (1992) who found one US variable to be significant in explaining other countries bond returns. The dividend yield on the US stock, however, is found to be insignificant.

\section{3: Market Efficiency Tests}

Following the development of a model for the change in implied volatility series in the previous section, we move on to devise a trading strategy that might exploit this potential predictability. This set of tests can be seen as market efficiency tests since we are using our fitted model of the change in

\footnotetext{
${ }^{5}$ In addition to testing for the day of the week effect, we include volume as another variable. As mentioned earlier, researchers have tried to link increases in volatility to increases in market liquidity. Thus we used volume
} 
implied volatility series to try to achieve abnormal returns. The regressions in table 4 are ex ante, with only lagged values of variables on the right hand side, and can therefore be used for forecasting. As Harvey and Whaley (1992) explained, the in-sample predictability in the series could either be the result of investors changing their view on the market upon the arrival of new information or it could be that the market is inefficient.

In order to use this strategy, we have to make out of sample forecasts of the change in implied volatility series. We test this strategy from the 1 st Jan 1995 to the 31st March 1996. For each day from the 1st of Jan 1995 (t), we regress the change in implied volatility series (including the change in implied volatility for $t$ ) on the set of information variables available up to and including day t. Using the estimated coefficients and information available for day $t$, we can make a forecast of the change in implied volatility for day $t+1$. For example, in order to make a forecast for the change in implied volatility for the $2^{\text {nd }}$ Jan 1995 on the $1^{\text {st }}$ Jan 1995, we first carry a regression of the change in implied volatility series (this series would include the change in implied volatility for the 1st of Jan 1995) on the set of information variable available up to the $1^{\text {st }}$ Jan. The estimated coefficients are then used on the information variables available on the 1st of Jan 1995 to make a prediction of the change in implied volatility for the $2^{\text {nd }}$ Jan 1995.

The trading strategy we use is quite simple: if our forecasts show that implied volatility will rise tomorrow then we buy the option because we expect the price to go up on the next day or vice versa if we predict a fall. There are no time restrictions as to when the position has to be taken on the next day except that it has to be as early as possible and only at the money options are to be bought or sold. We plan to close any position the day after it is opened, but if there are no reverse trades on that day we leave the position open until we can find a reverse trade to close it. Overall, of a total of 284 possible trading days of at the money options, we were unable to close the position on the next day for

as a proxy for market liquidity. Our results (not reported here) show that volume or changes in volume could not explain changes in implied volatility. 
only 45 days. Even though this option market is marked-to-market daily (as futures markets are), this should not make any difference to the total profit or loss, simply that the margin account at the Clearing House is changing daily and the total profit/loss will not be different from a market where there are no daily margin calls.

A simple check on how good the model forecasts are reveals that out of a possible 312 trading days over the test period, there were trades of at the money options on 284 days and out of that our predictions are right for 149 days (a 52.46\% success rate) in the sense that the signs were correctly predicted. The trading rule proved incorrect 128 times (e.g. we predicted a rise in implied volatility but the price of the option went down instead of up) and on seven occasions there was no change in the price of the option on the next day.

We use only a simple trading rule is used is that because of a lack of data, implying that we can not experiment with popular option trading strategies. For example, we might wish to buy or sell straddles $^{6}$, however because there are not enough simultaneous trades over our trading period (Jan 1995 - Mar 1996), we cannot buy/sell both puts and calls at the same time and exercise price for most of the trading days for the LIFFE options on bond futures ${ }^{7}$.

Moreover, because the price of the underlying asset (gilt futures) are not recorded for serial options ${ }^{5}$ we could not delta hedge the positions. Normally, when an option position is delta-hedged, the overall position would be insensitive to any changes that occur in the market, since if we buy one option and sell a certain amount (the hedge ratio) of the futures contract, the overall value of our position will not be affected by changes in the underlying asset. The fact that we can not delta hedge might not be a

\footnotetext{
${ }^{6}$ A long straddle is a position where we are long both the call and the put of the at the money option.

${ }^{7}$ The reason why we choose a straddle is in order to buy/sell volatility - if we expected volatility to rise, we would enter into a short straddle position, while if we expected volatility to remain constant or fall, we would sell a straddle.

${ }^{5}$ Options which mature between the regular options (Mar, Jun, Sept, Dec) are called serial options (e.g. Jan, Feb, Apr, etc.). Simultaneous recording of the futures and the option prices are available for regular options but
} 
serious problem because one can only be delta neutral for one instant in time since the price of the underlying asset changes all the time and as such the delta will not remain constant leaving us to adjust our futures position constantly and therefore greatly increasing the transaction costs.

For our trading strategy we assume that we are buying only one at the money option everyday and selling it as soon as possible during the following days. We do not employ a longer holding period because we cannot delta hedge our position and if we leave it open for more than one day we will be holding a very risky position which could wipe our profits or increase our losses. We test this strategy by using actual bid and offer prices of the options on Long Gilt futures that are traded on LIFFE. We look at this strategy from the point of view of both a private investor and a market maker. The investor will have to buy at the offer price and sell at the bid price thus losing the spread on each transaction, while this is not the case for the market maker. One assumption that we are making for both the private investor and the market maker is that they both will find a counter-party; this may seem a strong assumption, but since we are dealing with at the money options it would probably not be hard to find a counter-party who wants to deal at the quoted price.

Starting from an outlay of 0 (ignoring the margin requirement and assuming that one unit of the options contract is bought, held, or sold during each trade), we find that the private investor would not earn any abnormal profits. In fact, he would have made a loss of $£ 41.92$ over the out-of-sample period (Jan. 95 - March 96), due to the large transactions costs incurred in the course of the 284 trades made. On the other hand the market maker would have made a profit of $£ 30.03$ if he had followed our trading strategy. The cumulative profits of the market maker are shown in figure 3 . The market maker makes a steady flow of profits, with a fairly small maximum draw down.

\section{5: Conclusion}

not for the serial options. The delta of an option is defined as the change in the price of the option following a $£ 1$ change in the value of the underlying asset. 
We started this study by reporting that implied volatility is broadly agreed to represent the best estimate of future volatility and therefore that being able to model and to forecast implied volatility could be very useful and potentially profitable. We showed that using Black's European pricing formula, we could approximate the price of American options to determine implied volatility of at the money options. It was demonstrated that this method did not yield systematic pricing biases for closeto-the-money options. Using UK and US macroeconomic variables, we modelled the change in implied volatility series and then we moved on to devise a trading strategy to exploit our forecasts. Assuming that a counter-party was ready to deal in at the money options, we showed that a market maker could earn positive returns with an outlay of zero if we ignore the margin requirements. On the other hand, a private investor would not be able to earn positive returns because of the spread. We thus conclude that our results are broadly consistent with market efficiency.

\section{REFERENCES}

Barone-Adesi, G. and R.E. Whaley (1987) Efficient Analytic Approximation of American Option Values Journal of Finance Vol. 42, pp. 301-320

Beckers, S. (1981) Standard Deviations Implied in Option Process as Predictors of Future Price Variability Journal of Banking and Finance Vol. 5, pp. 363-382

Black, F. (1976) The Pricing of Commodity Contracts Journal of Financial Economics Vol. 3, pp. 167-179

Black, F. and M. Scholes (1973) The Pricing of Options and Corporate Liabilities Journal of Political Economy Vol. 81, pp. 637-659

Brooks, C. (1998) Forecasting Stock Return Volatility: Does Volume Help? Journal of Forecasting Vol. 17, pp. 59-80

Cakici, N., S. Chatterjee, A. Wolf, (1993) Empirical Tests of Valuation Models for Options on TNote and T-Bond Futures Journal of Futures Markets Vol. 13, pp. 1-14

Canina, L. and S. Figlewski (1993) The Information Content of Implied Volatility Review of Financial Studies Vol. 6, pp. 659-681

Clare, A.D. and S.H. Thomas (1992) International Evidence for the Predictability of Stock and Bond Returns Economics Letters Vol. 40, pp. 105-112

Day, T. and C. Lewis (1992) Stock Market Volatility and the Information Content of Stock Index Options Journal of Econometrics Vol. 52, pp. 267-287 
Elton, E.J., M.J. Gruber, and C.R. Blake (1995) Fundamental Economic Variables, Expected Returns and Bond Fund Performance Journal of Finance Vol. 50, pp. 1229-1256

Engle, R.F. (1982) Autoregressive Conditional Heteroskedasticity with Estimates of the Variance of United Kingdom Inflation Econometrica Vol. 50, pp. 987-1007

Franks, J.R. and E.S. Schwarz (1991) The Stochastic Behaviour of Market Variance Implied in the Prices of Index Options Economic Journal Vol. 101, pp. 1460-1475

Harvey, C.R. and R.E. Whaley (1992) Market Volatility Prediction and the Efficiency of the S\&P 100 Index Option Market Journal of Financial Economics Vol. 31, pp. 43-73

Ho, T.S., Stapleton, R.C. and Subrahmanyam, M.G. (1997) The Valuation of American Options with Stochastic Interest Rates: A Generalisation of the Geske-Johnson Technique Journal of Finance Vol. 52, pp.827-840.

Hull, J. and A. White (1987) The Pricing of Options on Assets with Stochastic Volatilities Journal of Finance Vol. 42, pp. 281-300

Jorion, P. (1995) Predicting Volatility in the Foreign Exchange Market Journal of Finance Vol. 50, pp. 507-528

Lamoureux, C. and W. Lastrapes (1993) Forecasting Stock Return Variance: Toward an Understanding of Stock Implied Volatilities Review of Financial Studies Vol. 6, pp. 293-326

Latané, H. and R.J. Rendleman (1976) Standard Deviation of Stock Price Ratios Implied by Option Premia Journal of Finance Vol. 31, pp. 369-382

Levin E.J. and R.E. Wright (1998) The Information Content of the Gilt-Equity Yield Ratio Manchester School Supplement, pp. 89-101

Ramaswamy, K. and S.M. Sundaresan (1985) The Valuation of Options on Futures Contracts Journal of Finance Vol. 40, pp. 1319-1340

Schmalensee R. and R.R. Trippi (1978) Common Stock Volatility Expectations Implied by Option Premia Journal of Finance Vol. 33, pp. 129-147

Stoll, H.R. and R.E. Whaley (1991) Expiration-Day Effects: What has Changed? Financial Analysts Journal Vol. 47, pp. 58-62 
Table 1: Summary Statistics of the Implied Volatility Data

\begin{tabular}{lrr}
\hline \multicolumn{2}{c}{$\begin{array}{c}\text { Implied Volatility } \\
\text { Mean }\end{array}$} & $\begin{array}{c}\text { Change in Implied } \\
\text { Volatility }\end{array}$ \\
\hline Variance & 0.0914 & -0.0002 \\
Kurtosis & 0.0005 & 0.0027 \\
Skewness & 0.0708 & $38.732^{* *}$ \\
Minimum & $0.5262^{*}$ & $1.5408^{* *}$ \\
Maximum & 0.0000 & -0.4814 \\
BJ-Norm & 0.1948 & 0.6667 \\
LB Q*(50) & $223.81^{* *}$ & $15792^{* *}$ \\
ACF(1) & $70003^{* *}$ & $255.7598^{* *}$ \\
ACF(2) & $0.9385^{* *}$ & $-0.2389^{* *}$ \\
ACF(3) & $0.9242^{* *}$ & -0.0038 \\
$\mathrm{ACF}(10)$ & $0.9120^{* *}$ & -0.0179 \\
$\mathrm{ACF}(50)$ & $0.8283^{* *}$ & $0.0449^{*}$ \\
$\mathrm{DF}$ & $0.6082^{* *}$ & $0.0438^{*}$ \\
$\mathrm{ADF}(5)$ & $-156.31^{* *}$ & - \\
$\mathrm{ARCH}(5)$ & $-37.4296^{* *}$ & - \\
\hline
\end{tabular}

Notes: * significant at the 5\% level; ** significant at the $1 \%$ level. LB Q*(50) indicates the Ljung Box test for autocorrelation using 50 lags. ACF(j) is the value of the autocorrelation coefficient at lag j. DF and $\operatorname{ADF}(5)$ are the Dickey Fuller and augmented Dickey Fuller test with 5 lags respectively. ARCH(5) is Engle's LM test for autocorrelation in the squared errors of up to fifth order. 
Table 2: Summary of Average Mispricing Errors of American Futures Options

Number of options

\begin{tabular}{lrcccc}
\hline & \multicolumn{5}{c}{ Panel A: (Actual Prices - Model Prices) } \\
& $\mathrm{T}<3$ & $3 \leq \mathrm{T}<6$ & $6 \leq \mathrm{T}<12$ & $\mathrm{~T} \geq 12$ & All $\mathrm{T}$ \\
\hline $\mathrm{F} / \mathrm{K}<0.98$ & 0.003 & 0.009 & 0.018 & 0.046 & 0.026 \\
& 5114 & 5316 & 10026 & 15543 & 35999 \\
$0.98 \leq \mathrm{F} / \mathrm{K}<1.02$ & 0.039 & 0.056 & 0.078 & 0.116 & 0.088 \\
& 2489 & 2636 & 5048 & 9115 & 19288 \\
$\mathrm{~F} / \mathrm{K} \geq 1.02$ & 0.032 & 0.065 & 0.149 & 0.248 & 0.160 \\
& 6119 & 6303 & 10949 & 17146 & 40517 \\
$\mathrm{All} \mathrm{F} / \mathrm{K}$ & 0.022 & 0.042 & 0.085 & 0.144 & 0.095 \\
& 13722 & 14255 & 26023 & 41804 & 95804 \\
\hline
\end{tabular}

Panel B: (Actual Prices - Model Prices) / Actual Prices

$\mathrm{T}<3 \quad 3 \leq \mathrm{T}<6 \quad 6 \leq \mathrm{T}<12 \quad \mathrm{~T} \geq 12 \quad$ All $\mathrm{T}$

\begin{tabular}{lccccc}
\hline $\mathrm{F} / \mathrm{K}<0.98$ & 0.023 & 0.015 & 0.011 & 0.018 & 0.017 \\
$0.98 \leq \mathrm{F} / \mathrm{K}<1.02$ & 0.022 & 0.018 & 0.021 & 0.031 & 0.026 \\
$\mathrm{~F} / \mathrm{K} \geq 1.02$ & 0.010 & 0.022 & 0.024 & 0.043 & 0.029 \\
All F/K & 0.018 & 0.018 & 0.019 & 0.031 & 0.026 \\
\hline
\end{tabular}

In order to calculate the mispricing, model prices are first estimated using the Black (1976) formula. These are then subtracted from actual market prices. The entries above are the averages of the difference in prices for each category in Panel A, and the average differences as a proportion of the option price, in Panel B, together with the number of options in that category. 
Table 3: Regressions results for the day of the week effect

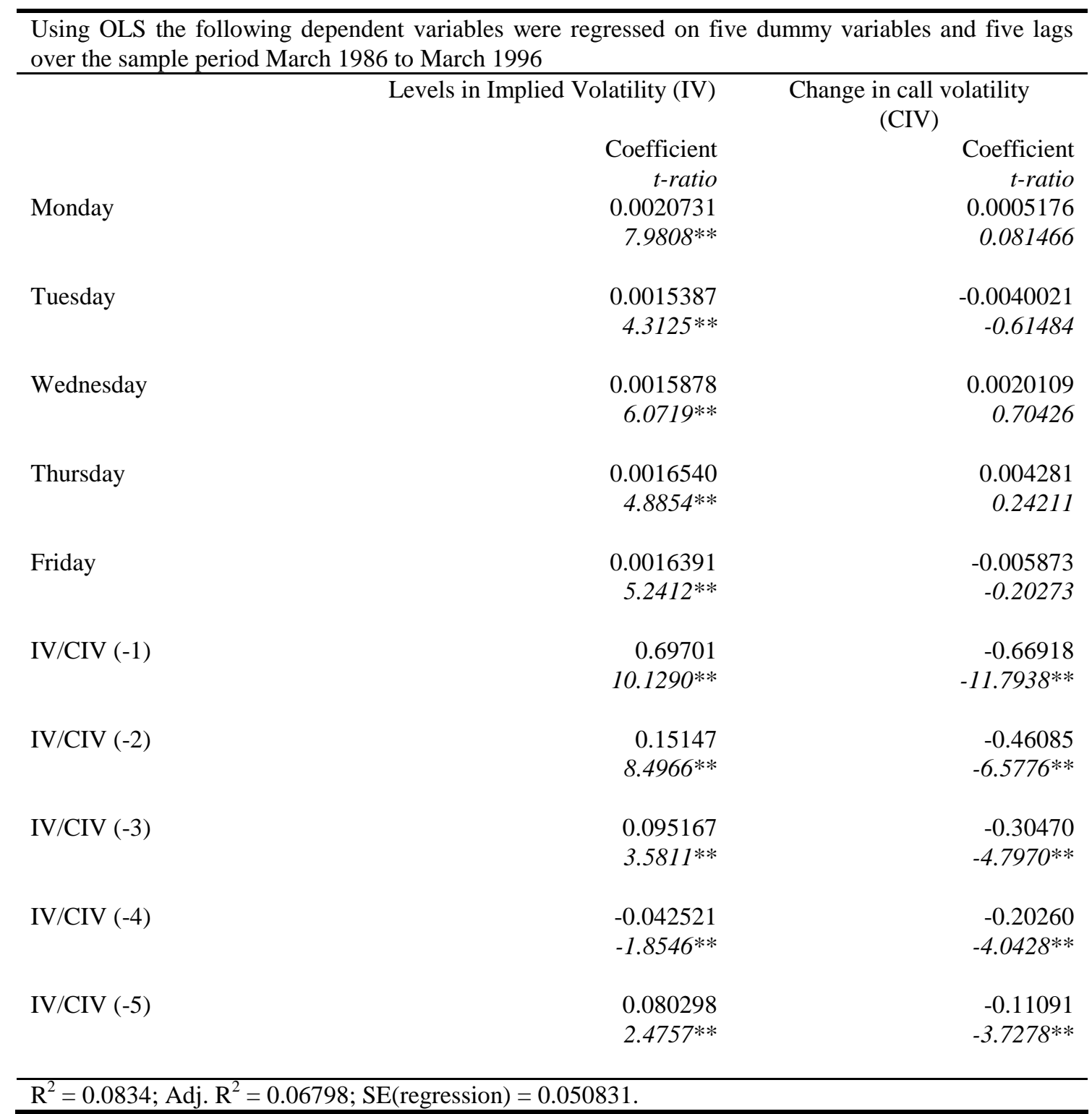

Notes: $*$ and $* *$ indicate significance at the $10 \%$ and $5 \%$ levels respectively. t-ratios in italics are calculated using heteroscedasticity-robust standard errors. 
Table 4: Modelling the Change in Implied Volatility of

\section{Options on Long Gilt Futures}

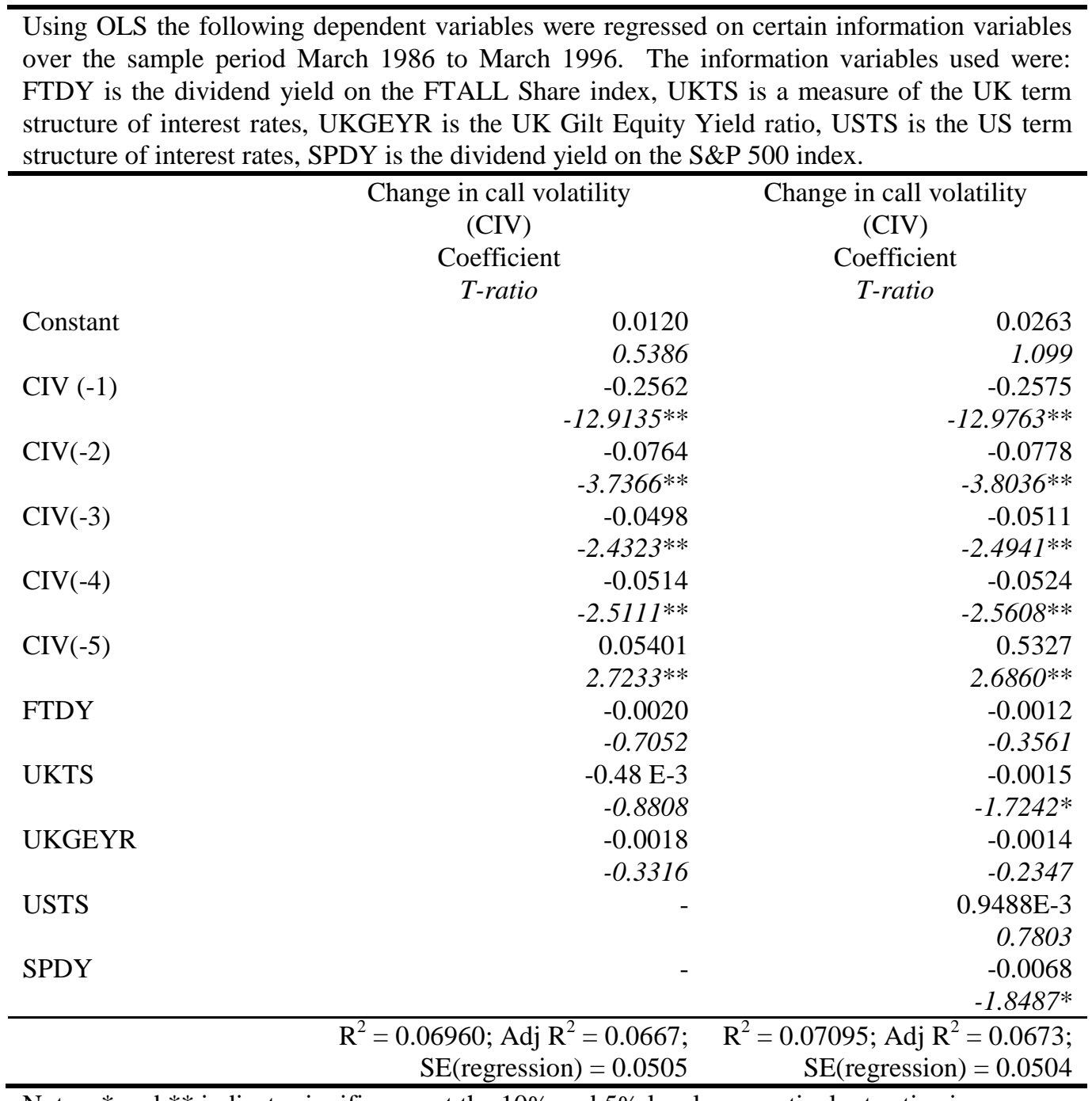

Notes: $*$ and $* *$ indicate significance at the $10 \%$ and $5 \%$ levels respectively. t-ratios in italics are calculated using heteroscedasticity-robust standard errors. 
Figure 1: Implied Volatility of Options on Long Gilt Futures

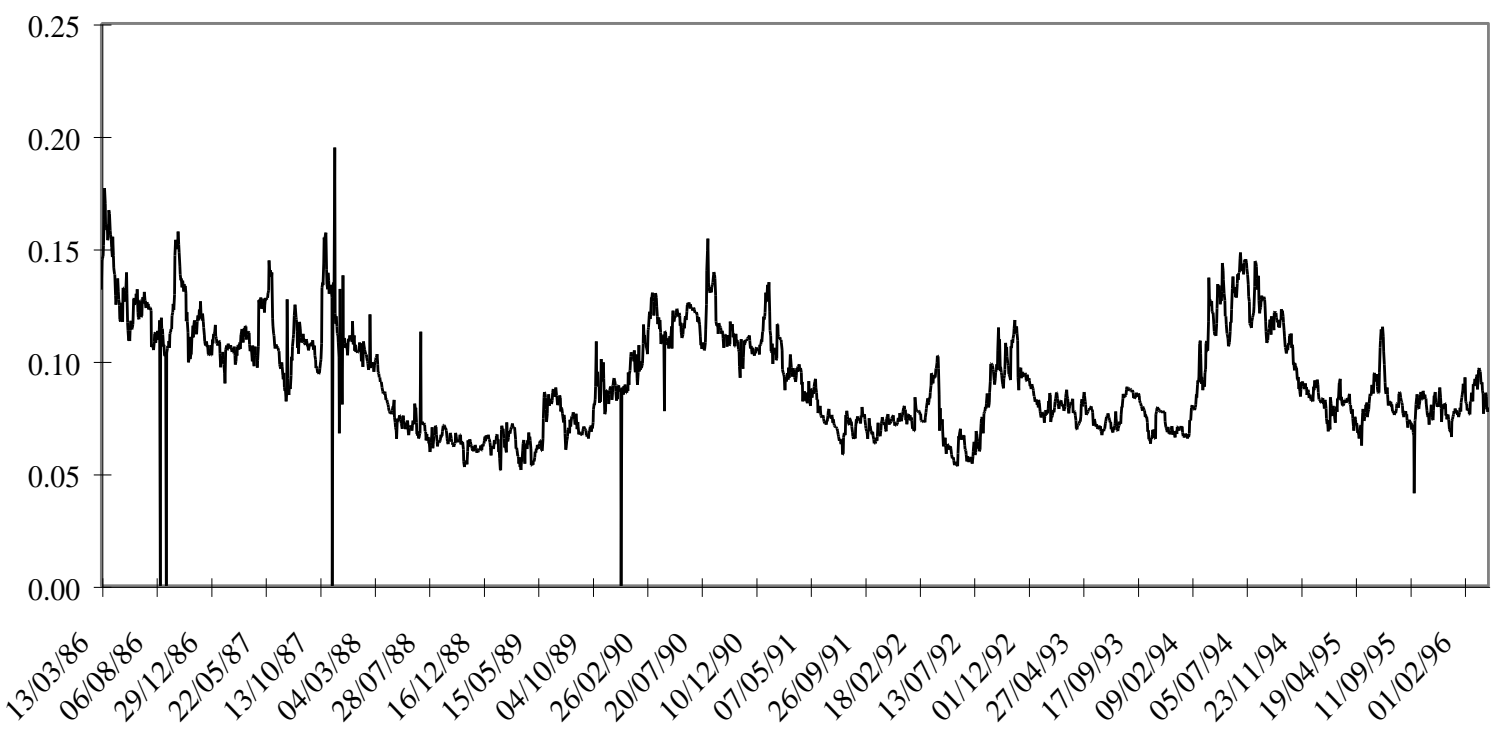

Figure 2: Change in Implied Volatility of Options on Long Gilt Futures

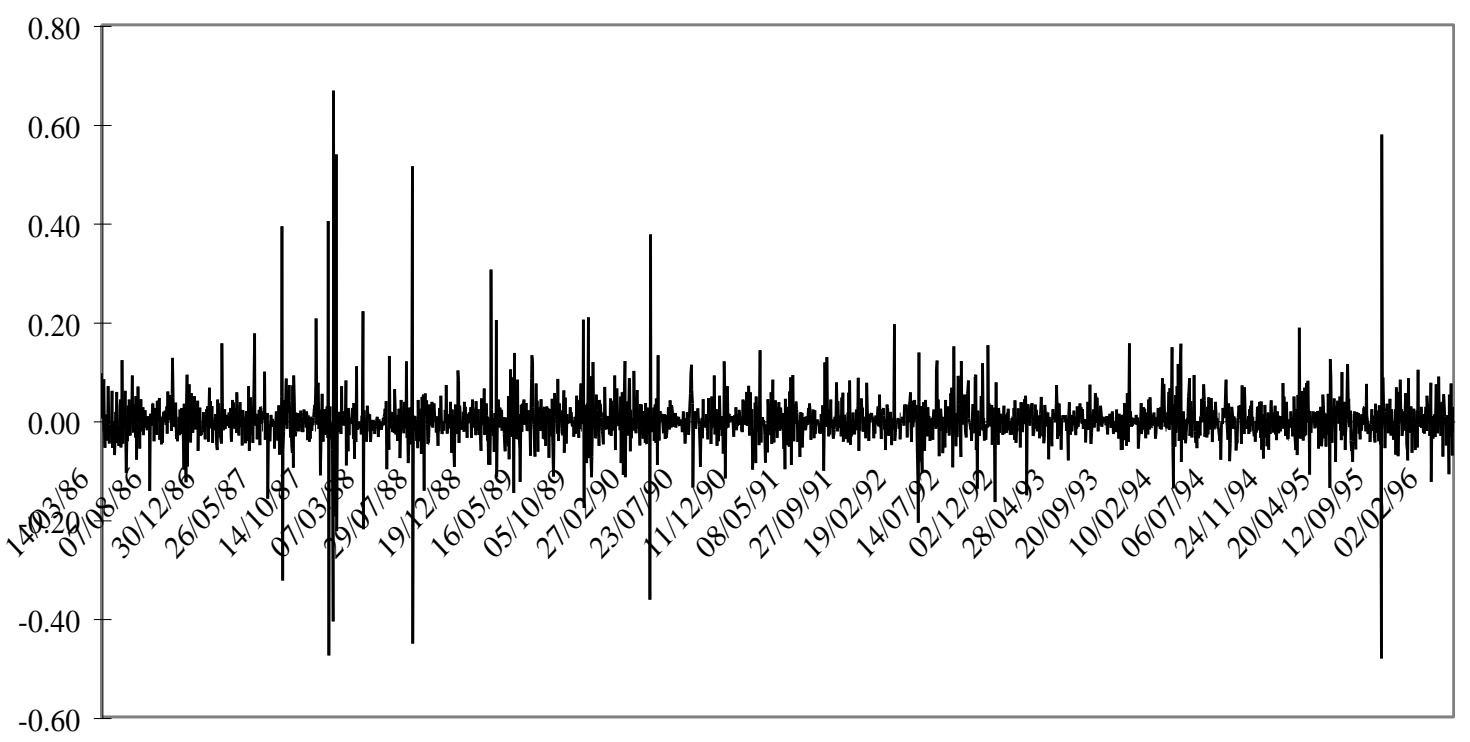


Figure 3:

Cumulative Profits of the Market Maker (January 1995-March 1996)

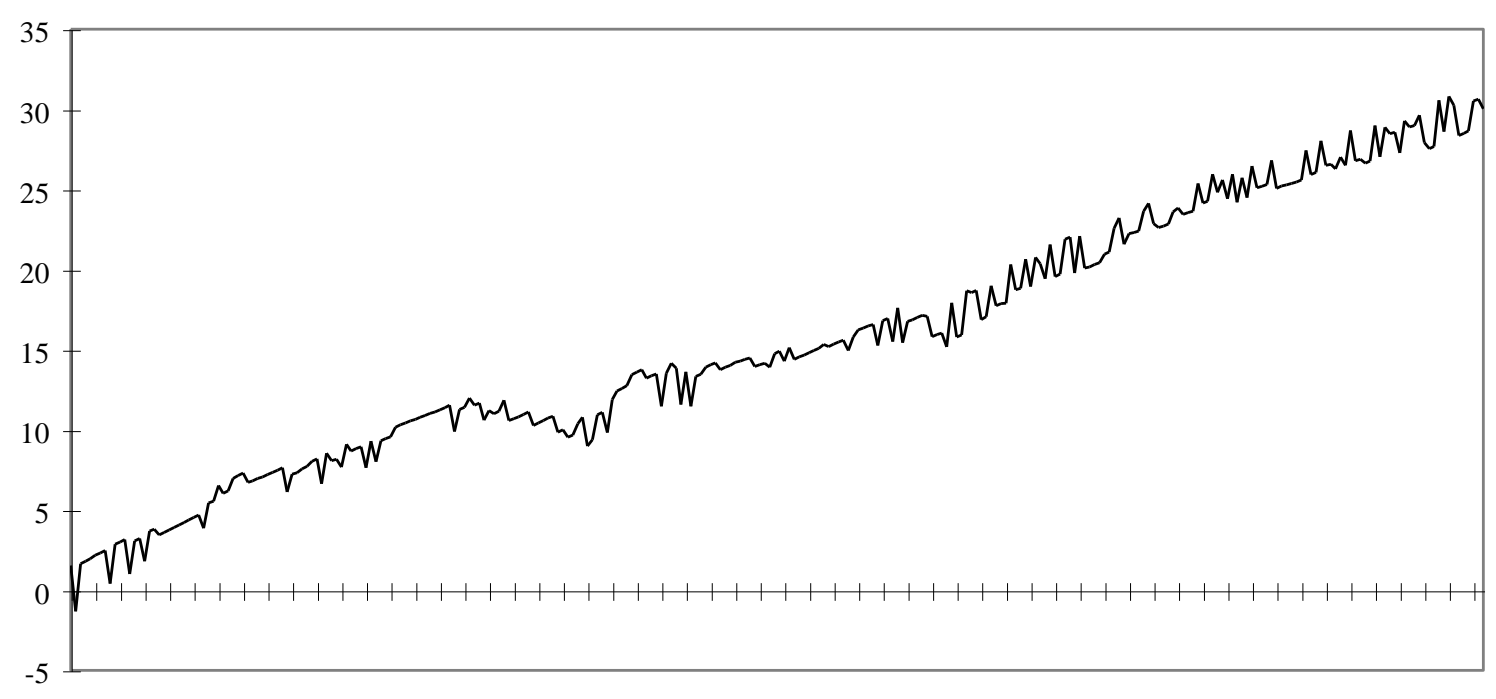

